\title{
Erratum to: CXCL12 / CXCR4 / CXCR7 chemokine axis and cancer progression
}

\author{
Xueqing Sun • Guangcun Cheng • Mingang Hao • \\ Jianghua Zheng $\cdot$ Xiaoming Zhou • Jian Zhang • \\ Russell S. Taichman • Kenneth J. Pienta • Jianhua Wang
}

Published online: 12 November 2010

(C) Springer Science+Business Media, LLC 2010

Erratum to: Cancer Metastasis Rev (2010) 29:709-722

\section{DOI 10.1007/s10555-010-9256-x}

The original version of this article unfortunately contained a mistake. An error has been found in Figure 1. The correct version is given below

The online version of the original article can be found at http://dx.doi.org/10.1007/s10555-010-9256-x.

$\mathrm{X}$. Sun $\cdot$ G. Cheng $\cdot$ M. Hao $\cdot$ J. Zheng $\cdot$ X. Zhou $\cdot$ J. Wang $(\bowtie)$

Department of Biochemistry and Molecular \& Cell Biology,

Key Laboratory of Cell Differentiation and Apoptosis of Chinese,

Ministry of Education, Institute of Medical Science,

Shanghai Jiao Tong University School of Medicine,

Shanghai 200025, People's Republic of China

e-mail: jianhuaw2007@gmail.com

J. Zhang $\cdot$ K. J. Pienta

Department of Internal Medicine and Urology,

University of Michigan,

Ann Arbor, MI 48109, USA

\section{R. S. Taichman}

Department of Periodontics \& Oral Medicine, University of Michigan School of Dentistry,

Ann Arbor, MI 48109, USA 


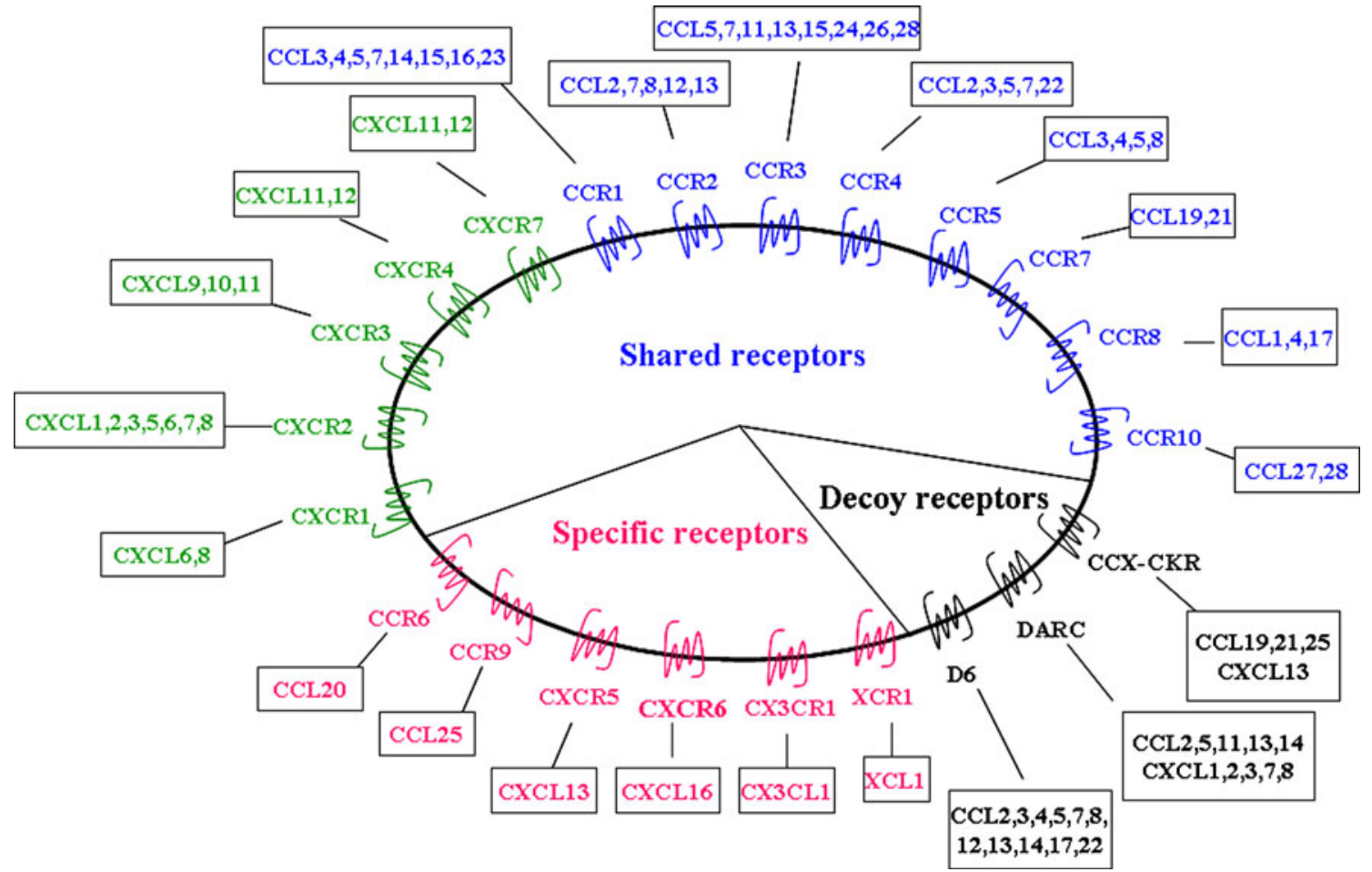

Fig. 1 Chemokine family and their cognate receptors. Most chemokines can bind multiple receptors, and a single receptor can bind multiple chemokines, as shown in this case for most CC (blue) and
CXC (green) chemokines. Decoy receptors (black) can also interact with multiple chemokines. By contrast, a minority of receptors ( $\mathrm{red}$ ) have only one ligand 